\title{
Motif dan Kepentingan China dalam Pembentukan Regional Comprehensive Economic Partnership (RCEP)
}

\author{
Muhammad Ferdy Pratama ${ }^{1}$, Palwa Ibnu Sosa ${ }^{2}$, Tegar Yulianto ${ }^{3}$ \\ 1,2,3 Jurusan Ilmu Hubungan Internasional, FISIP, Universitas Sriwijaya, Palembang, Indonesia
}

\begin{tabular}{l}
\hline \hline Article Info \\
\hline Article history: \\
Received 24 November 2021 \\
Publish 01 Januari 2022 \\
\\
\hline Keywords: \\
RCEP \\
China \\
Chinese motives \\
China's economy
\end{tabular}

\section{Info Artikel}

Article history:

Diterima 24 November 2021

Publis 01 Januari 2022

\begin{abstract}
The establishment of the Regional Comprehensive Economic Partnership (RCEP) began because of the conflict between China and Japan. The establishment of RCEP is to create the largest trade agreement in the world because this cooperation unites regional countries with large economies. China as a country that has the largest economic level among RCEP member countries makes China control most of the market in the region. This RCEP helps China in dealing with the trade war between China and the United States, although it has not yet had a big impact. This paper uses a qualitative method and focuses on China's motives in determining the RCEP. The results of this study confirm that China's motive in determining the RCEP is to counter-balance with the TPP and China's good image to Southeast Asian countries. In addition, RCEP has a significant impact on the Chinese economy.

\section{ABSTRACT}

Terbentuknya Regional Comprehensive Economic Partnership (RCEP) dimuali karena konflik yang terjadi antara China dan Jepang. Berdirinya RCEP ialah menciptakan kesepakatan perdagangan terbesar didunia karena Kerjasama ini menyatukan negara-negara kawasan dengan perekenomian yang besar. China sebagai negara yang memiliki tingkat ekonomi trerbesar diantara negara-negara anggota RCEP membuat China menguasai sebagian besar pasar dalam kawasan. RCEP ini membantu China dalam menghadapi perang dagang antara China dan Amerika Serikat walaupun belum memiliki dampak yang besar. Penulisan ini menggunakan metode kualitatif dan berfokus kepada motif China dalam penetapan RCEP. Hasil dari penelitian ini menejaskan bahwa motif China dalam penetapan RCEP adalah untuk counter-balance dengan TPP dan citra baik China kepada negara kawasan Asia Tengara. Sealain itu RCEP memiliki dampak yang cukup signifikan terhadap perekonomian China.
\end{abstract}

This is an open access article under the Lisensi Creative Commons AtribusiBerbagiSerupa 4.0 Internasional

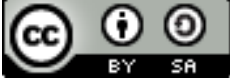

Corresponding Author:

Palwa Ibnu Sosa,

Jurusan Ilmu Hubungan Internasional, FISIP Universitas Sriwijaya, Palembang, Indonesia

Email: Palwaibs@gmail.com

\section{PENDAHULUAN}

Globalisasi menuntut terjadinya peleburan batas-batas yuridis antar wilayah di dunia, Hal ini membawa perubahan dalam segala aspek. Aspek Ekonomi merupakan aspek yang sangat melekat pada proses globalisasi. Leburnya batas-batas wilayah mendorong antarnegara saling mengintegrasi dan terciptanya regional-regionalisme. Salah satu regionalisme yang cukup besar di dunia ialah Uni Eropa, APEC, ASEAN dan lain-lain. Hal ini pula yang meningkatkan arus perdagangan antarnegara yang melahirkan liberalasi Perdagangan. Bahkan kawan asia pasifik merupakan kawasan dengan zona perdagangan bebas terbesar di Dunia hal ini dibuktikan pada tahun 2015 ada sekitar 160 perjanjian perdagangan bebas yang telah ditanda tangani APEC. 
Melihat kenaikan kerjasama Perdagangan Bebas merupakan suatu sebuah progresif yang signifikan di kawasan Asia Pasifik. Hal ini dibuktikan dengan dibentuknya kerjasama yang besar dan kompleks, Seperti ada kerjasama RCEP (Regional Comprehensive Economic Partnership). RCEP pada mulanya diresmikan pada pertemuan puncak ke 21 ASEAN di kota Phnom Penh, Kamboja November 2012. selama 8 tahun Terkait RCEP ini, akhirnya disahkan dalam Konferensi Tingkat Tinggi pada 15 November 2020 dengan beranggotakan 10 negara ASEAN serta negara Mitra FTA Yaitu Korea Selatan, Jepang, Australia, Cina dan Selandia baru. Perjanjian RCEP ini juga merupakan pengintergrasian ekonomi kawasan dengan total sebesar $\$ 24,7$ Triliun bahkan jumlah ini ialah 30,2\$ PDB Dunia ditahun 2019.

Sementara itu, FDI di RCEP mencapai \$379,9 Miliar dengan jumlah yang lebih besar dari NAFTA. Selain itu Kerjasama RCEP ini sangat menarik karena Perjanjianya yang sangat Komperhensif baik dari konteks maupun ikatan komitmen yang pernah dijalani oleh ASEAN. Perjanjian yang ada dalam RECP meliputi 16 anneces dan 20 bab yang menatur ketentuan asal barang, Prosude kepabenan serta fasilitasi perdagangan, mengatur perdagangan berang, pengamanan perdagangan, investasi, kekayaan intelektual, jasa, finansial, telekomunikasi serta penyelesaian sengketa.

Perjanjian RCEP ini jika dijelaskan secara singkat terdiri dari 3 cakupan penting, yaitu;

a. Akses pasar yang meliputi perdagangan barang maupun jasa, serta cakupan bidang investasi.

b. Cooperation, ialah kerja sama yang meliputi bidang small dan medium seperti mendukung program berbasis UKM serta mendorong sharing informasi sharing bisnis atau regulasi antarnegara serta bekerja sama dalam memberikan bantuan teknis untuk peningkatan pembangunan yang efektif, inklusif dan efisien.

c. Rules ialah aturan yang mencakup technical regulation and conformity assessment procedures, Penyelesaian sengketa, movement on natural person, custom procedures dan fasilitasi perdagangan, pengadaan pemerintah, kekayaan intelektual, electronic commerce dan lain-lain.

Cakupan Kerjasama RCEP ini berada dibawah koridor atau sesuai relevenisasi yang Setujui Oleh WTO (World Trade Organization) dan GATT (General Agreement On Tariffs and Trade). Sehingga Hal ini diharapkan menjadi optimisme baru ekonomi kawasan, mengingat pandemi yang sedang terjadi berimbas pada perekonomian.

Jika menelaah lebih lanjut terkait RCEP, dalam pembentukanya bermula pada KTT ASEAN ke-19 pada tahun 2011 di bali, indonesia dalam termal The ASEAN Framework for RECP (Regional Comprehensive Economic Partnership). Lalu ditahun selanjutnya 2012, dilanjutkanya diskusi lebih lanjut dalam ASEAN Summit di November 2012. Namun yang paling menarik dalam penginisiasian RCEP ini, walaupun perundingan ini baru dimulai di tahun 2012. China Berusaha berinisasif mendorong agar RCEP ini cepat dirampungkan dalam perundingannya serta kerjasama RCEP yang perlu direalisasikan secepatnya. Tindakan China ini semakin mencolok pada tahun 2015, dimana china berusaha menyelesaikan proses perundingan. Bahkan di beberapa perundingan dalam pembentukan Kerjasama RCEP, China berusaha mengambil alih proses perundingan dengan maksud agar RCEP lebih cepat diselesaikan.

Kasus serupa ini juga pernah terjadi di TPP (Trans Pacific Partnership), dalam perundingan pembentukan kerjasama tersebut AS berusaha memimpin Perundingan dan akhirnya dalam partnership terdapat dominasi besar AS. Sehingga dalam hal ini sangat terlihat, bahwa dalam Kerjasama RCEP terdapat Kepentingan besar China di RCEP terkhusus kawasan Asia Pasific. Berbagai tindakan China dalam menginisasiasi ini juga menjadikan bentuk bahwa china memiliki motif besar di RCEP. Pada awalnya india merupakan kandidat anggota dari RCEP, Namun ia akhirnya mengundurkan diri karena kekhawatiran dengan adanya china dalam kerjasama Ekonomi ini dapat merugikan India terutama pasar Domestiknya. Dengan motif ini kami sangat tertarik membahas lebih lanjut terkait Kepentingan China, karena berdasarkan penelitian sederhana yang kami lakukan china memiliki usaha besar dalam menginisiasi RCEP serta terdapat beberapa 
kekhawatiran negara besar dengan adanya. Sehingga jurnal kami berusaha menjelaskan kepentingan lebih lanjut terkait China dalam RCEP.

\section{LANDASAN TEORI}

Landasan teori merupakan kerangka berpikir dalam membuat suatu karya tulis ilmiah. Landasan teori ini yang kemudian akan digunakan untuk melakukan analisis tentang kasus yang akan diteliti. Untuk membahas suatu kasus harus memiliki teori dan pandangan yang jelas, sehingga perlu untuk menjelaskan teori dan perspektif yang digunakan, serta konsep yang digunakan dalam penelitian ini.

Penelitian ini berusaha untuk menjelaskan kepentingan China dalam proses pembentukan perjanjian RCEP (Regional Comprehensive Economic Partnership) melalui perspektif neorealisme dimana sistem dunia yang anarki tetapi dengan adanya kerjasama internasional maka memberi tekanan pada negara sebagai aktor untuk melakukan kerjasama salah satunya kerjasama dalam bidang ekonomi. Walaupun negara dapat melakukan perdagangan internasional secara bilateral tetapi dengan proses integrasi kawasan akan memudahkan negara dalam menjalankan kepentingan nasionalnya dalam bidang ekonomi. Dengan adanya suatu wadah atau tempat untuk memaksimalkan pasar dan keuntungan suatu negara.

Teori neorealisme merupakan pengembangan dari teori realisme yang mengutamakan balance of power tetapi tidak menutup adanya kerjasama melalui organisasi internasional seperti yang ada pada liberalisme. Kenneth Waltz memiliki pandangan bahwa negara negara tidak harus mengutamakan kekuatan sebagai suatu hal yang sangat penting hingga mengabaikan faktor lainnya. Hal tersebut didasari oleh Sistem Internasional akan membuat negara lain akan merasa terancam dan akan berbalik menyerang negara yang berfokus pada peningkatan kekuatan.

Sistem internasional yang anarki memiliki konsekuensi, diantaranya tidak ada suatu otoritas yang dapat menjamin keamanan setiap negara. Selanjutnya yaitu self-help dimana negara hanya berusaha untuk menolong dirinya sendiri agar tidak menjadi korban atas perilaku dari negara lain. Menurut Waltz keadaan yang anarki dari sistem internasional membuat negara melakukan berbagai cara untuk mempertahankan diri dari ancaman negara lain. Dalam neorealisme negara merupakan aktor utama. Sistem internasional yang anarki membuat negara yang dominan dalam suatu kerjasama regional akan berpeluang mendapatkan keuntungan dan menguasai perekonomian di kawasan tersebut. (Dugis, 2016).

\section{METODE PENELITIAN}

Penulis melakukan penelitian terhadap permasalahan ini menggunakan metode kualitatif melalui data yang telah dikumpulkan dengan melakukan pengamatan secara seksama dalam memahami permasalahan ini. Penggunaan metode kualitatif disini berusaha untuk menggambarkan bagaimana fenomena ini terjadi secara menyeluruh. Penelitian kualitatif menggunakan data-data sekunder berupa tulisan maupun angka sesuai dengan permasalahan yang dikaji. Penelitian yang dikaji dalam permasalahan ini adalah "Motif China dalam Penetapan RCEP" yang menjabarkan kepentingan dan motif China dalam RCEP ini. Penelitian ini menggunakan teori neorealisme sebagai mata pisau untuk menjeaskan bahwa China masih membutuhkan organisasi internasional untuk menjalankan kepentingan nasionalnya.

\section{HASIL PENELITIAN DAN PEMBAHASAN 3.1 Sejarah Terbentuknya RCEP}

Awal mula terbentuknya Regional Comprehensive Economic Partnership (RCEP) dikarenakan konflik yang terjadi antara China dan Jepang. Cina dan Jepang memiliki pandangan yang berbeda tentang struktur ekonomi regional yang paling tepat dalam hal keanggotaan dan agenda. Perjuangan antara keduanya untuk dominasi regional dapat ditelusuri 
kembali tidak lama setelah krisis keuangan Asia yaitu pada tahun 1997/1998. Jepang pada saat itu ingin berusaha untuk membentuk Asian Monetary Fund (AMF) tetapi berhasil di block oleh Amerika (Narine, 2003). Di bidang perdagangan, pada November 2000, China mengusulkan untuk melakukan studi bersama tentang ASEAN-China FTA, yang diterima oleh ASEAN. Pada KTT ASEAN-China pada November 2001, kedua pihak sepakat untuk membentuk ASEANChina FTA pada 2010. Sekitar pertengahan 2000-an, persaingan antara kedua negara pindah ke keanggotaan dan agenda politik. Hasil studi CEPEA dilaporkan ke ASEAN+6 EMM dan hasil studi EAFTA ke ASEAN+3 EMM pada Agustus 2009. proposal China menekankan pada liberalisasi perdagangan barang, sedangkan proposal Jepang menekankan pada isu non-barang seperti investasi dan kekayaan intelektual. Sementara politik keanggotaan telah menarik perhatian, politik agenda setting sama pentingnya. Jika kesepakatan terbatas pada perdagangan barang, China akan menjadi pemain dominan dalam negosiasi, mengingat ukuran pasar domestiknya. ASEAN tidak dapat memutuskan proposal mana yang akan didukung sehingga berusaha menjembatani keduanya. Ketidaksepakatan antara China dan Jepang mengenai keanggotaan dan agenda yang tepat merupakan hal yang serius sebagaimana dibuktikan oleh dua studi berbeda tentang EAFTA dan CEPEA yang dilaporkan ke forum yang berbeda.

China dan Jepang membuat proposal bersama tentang kerjasama ekonomi Asia Timur pada Agustus 2011. Mereka menyarankan pembentukan Kelompok Kerja, di mana EAFTA dan CEPEA dapat dibahas, sebelum akhir 2011 untuk mencakup topik-topik berikut: (i) perdagangan barang, (ii) perdagangan jasa, dan (iii) investasi. Mereka juga mengusulkan untuk menyerahkan hasil studi kepada para menteri dan pemimpin pada tahun 2012. Proposal tersebut dengan jelas menyatakan bahwa peserta akan terbatas pada ASEAN dan mitra FTA ASEAN, dan bahwa ASEAN akan memimpin inisiatif ini. Pada KTT ASEAN ke-19 di Bali pada 17 November 2011, ASEAN memutuskan untuk mengesahkan RCEP. East Asia Summit (EAS) yang diadakan 2 hari kemudian, cukup "mencatat" keputusan ASEAN karena EAS termasuk AS yang mungkin berusaha menghalangi kemajuan RCEP. Proposal tersebut dengan jelas menyatakan bahwa peserta akan terbatas pada ASEAN dan mitra FTA ASEAN, dan bahwa ASEAN akan memimpin inisiatif ini. Pada KTT ASEAN ke-19 di Bali pada 17 November 2011, ASEAN memutuskan untuk mengesahkan RCEP. Pada bulan Agustus 2012, konsultasi ASEAN Economic Ministers Plus FTA Partners pertama diadakan. Pada November 2012, ASEAN dan mitra FTA-nya secara resmi sepakat untuk meluncurkan negosiasi RCEP. Pada saat yang sama, ASEAN dan mitra FTA-nya memutuskan Prinsip dan Tujuan Panduan untuk Negosiasi RCEP. Kemajuan yang dicapai pada tahun 2011 mengenai FTA trilateral ChinaJepang-Republik Korea, yang dikenal sebagai CJK FTA, juga patut mendapat perhatian. Pada KTT trilateral pada Oktober 2009, ketiga negara sepakat untuk meluncurkan studi tentang CJK FTA dengan tanggal penyelesaian asli sebelum akhir 2012. Masuk akal jika China ingin mempercepat proses negosiasi CJK FTA dan RCEP untuk bersaing dengan TPP. Pada saat yang sama, tujuan utama Jepang dalam mendukung RCEP adalah untuk secara efektif menggunakan "kartu China" dengan AS ketika partisipasinya dalam TPP dipertaruhkan. Tidak jelas apakah upaya bersama antara China dan Jepang ini merupakan fenomena sementara. Besar kemungkinan China akan terus melakukan upaya pembentukan RCEP secepatnya agar dapat bersaing dengan TPP. (Hamanaka, 2014)

\subsection{Tujuan dan Manfaat dibentuknya RCEP}

Sebagai buku aturan tunggal, RCEP memiliki nilai tambah dan dapat mendorong pengembangan dan perluasan rantai pasokan antar anggota. Perjanjian tersebut mencakup kerjasama teknis dan pengembangan kapasitas untuk mendukung tindakan mereka berdasarkan perjanjian. RCEP juga memberikan fleksibilitas yang cukup besar (misalnya, dalam hal jadwal pelaksanaan) dan mencakup ketentuan khusus untuk perlakuan berbeda, terutama untuk Kamboja, Republik Demokratik Rakyat Laos (Republik Demokratik Rakyat Laos), Myanmar 
dan Vietnam. Hal ini memastikan bahwa ekonomi pada tingkat perkembangan yang berbeda, perusahaan dengan ukuran yang berbeda, dan pemangku kepentingan yang lebih luas memiliki kesempatan untuk memperoleh manfaat maksimal dari pemenuhan komitmen mereka (BRIEFS, 2020). Dari penjelasan diatas ini berarti RCEP dapat berguna sebagai perluasan akses pasar yang mana benefits itu dapat kita lihat dari program seperti ASEAN-China FTA, ASEAN-Japan CEP, ASEAN-Korea FTA, ASEAN-India FTA, ASEAN-Australia-New Zealand FTA, dan 5 ASEAN+1FTA) (Syahdani).

Adapun manfaat yang didapat jika bergabung seperti yang paling utama adalah tentang perdagangan barang. Kontribusi utama RCEP dalam perdagangan barang adalah menggabungkan kesepakatan yang ada, yang membawa Asia selangkah lebih dekat ke blok perdagangan regional. Ini karena, meskipun RCEP akan meningkatkan akses pasar, dengan penghapusan tarif dan kuota di lebih dari 65\% barang yang diperdagangkan (Secretariat, ASEAN Hits Historic Milestone with Signing of RCEP, 2020), RCEP diperkirakan tidak akan mengarah pada pengurangan tarif keseluruhan yang besar karena perjanjian perdagangan sudah ada di antara banyak anggota. RCEP juga akan berbuat lebih sedikit untuk menghapus tarif pada produk pertanian dan perikanan daripada CPTPP6 atau Perjanjian Kemitraan Ekonomi Jepang-Uni Eropa, berdasarkan pertimbangan tentang kondisi bagi banyak eksportir makanan di blok tersebut. Manfaat lain yang dapat ditemukan adalah Rules of origin, Ini berarti produk yang memenuhi kriteria asal RCEP tunduk pada aturan yang sama di seluruh 15 negara anggota. Aturan asal umum RCEP dapat mendorong proses produksi kontemporer dan pengaturan logistik perdagangan. Kemudahan pergerakan barang di seluruh wilayah melalui anggota RCEP dan penggunaan hub distribusi regional akan ditingkatkan (Trade, 2020). Mengikuti praktik yang biasa, bab aturan asal RCEP mencantumkan operasi dan proses minimal yang dianggap tidak cukup untuk memberikan status asal pada barang yang menggunakan bahan bukan asal. Jika suatu barang tidak memenuhi perubahan dalam aturan klasifikasi tarif dalam lampiran aturan khusus produk, bab ini menetapkan aturan de minimis tertentu yang melaluinya barang masih dapat memperoleh status asal (Secretariat, Summary of the Regional Comprehensive Economic, 2020).

Dapat ditarik kesimpulan bahwa dengan bergabungnya ke RCEP, negara-negara mitra, khususnya negara-negara anggota ASEAN, akan mendapatkan keuntungan dari peningkatan ekspor, peningkatan investasi, dan lebih banyak kesempatan untuk berpartisipasi dalam rantai pasokan regional (regional value chains) karena peningkatan akses pasar. Perjanjian tersebut dapat membantu lebih banyak perusahaan ASEAN berintegrasi ke dalam rantai pasokan regional hingga global dan memperluas bisnis mereka di negara-negara anggota RCEP dan pasar global. Namun, karena lingkungan ekonomi dan struktur industri yang berbeda di negaranegara ASEAN, hal ini menyebabkan perbedaan tingkat manfaat yang dirasakan dalam RCEP.

\subsection{Perkembangan RCEP}

Pada tahun 2018, RCEP belum menyelesaikan negosiasi antara 16 negara. Hingga tahun 2019, ke-16 negara tersebut masih belum menyelesaikan negosiasi RCEP karena ditentang oleh India, seorang pejabat India mengatakan bahwa India tidak dapat bergabung dengan RCEP berdasarkan ketentuannya saat ini, dan India tidak berpartisipasi dalam pertemuan negosiasi berikutnya. Pada November 2020, terjadi dua perubahan besar yang akan berdampak besar bagi ASEAN dan Asia Timur di tengah meningkatnya proteksionisme dan penyebaran global COVID-19. Pertama, Joe Biden memenangkan pemilihan presiden AS 2020 yang diadakan pada 6 November. Biden menjabat sebagai presiden AS pada Januari 2021 dan akan mengubah kebijakan perdagangan Trump saat ini. Selanjutnya, dan yang sangat penting, kesepakatan RCEP akhirnya ditandatangani oleh para pemimpin 15 negara Asia Timur pada KTT RCEP ke4 pada 15 November 2020. Ini merupakan hasil yang luar biasa bagi integrasi ekonomi ASEAN dan Asia Timur. Langkah-langkah lebih lanjut yang diambil sehubungan dengan ratifikasi 
RCEP sedang dilakukan dengan cara yang konsisten dengan prosedur pembuatan perjanjian Australia. Langkah-langkah tersebut termasuk pengajuan Perjanjian di Parlemen Australia, yang terjadi pada 18 Maret 2021. Termasuk juga pertimbangan RCEP oleh Joint Standing Committee on Treaties (JSCOT). JSCOT telah menyelesaikan penyelidikannya terhadap RCEP, dan telah merekomendasikan agar Pemerintah Australia meratifikasi RCEP. Undang-undang pelaksana RCEP diperkenalkan di Dewan Perwakilan Rakyat pada 1 September 2021. Parlemen Australia mengesahkan undang-undang ini pada 21 Oktober 2021 setelah perdebatan di Dewan Perwakilan Rakyat. Perwakilan dan Senat. Pemerintah sekarang melanjutkan dengan langkahlangkah yang tersisa menuju ratifikasi Australia atas Perjanjian RCEP. Brunei Darussalam, Cina, Jepang dan Singapura telah meratifikasi Perjanjian. Perjanjian RCEP akan mulai berlaku 60 hari setelah enam Negara Anggota ASEAN dan tiga Negara Anggota non-ASEAN telah meratifikasi Perjanjian. Perjanjian RCEP akan mulai berlaku 60 hari setelah enam Negara Anggota ASEAN dan tiga Negara Anggota non-ASEAN telah meratifikasi Perjanjian.

3.4 Motif \& Kepentingan China dalam The Regional Comprehensive Economic Partnership (RCEP)

Berdirinya RCEP ialah menciptakan kesepakatan perdagangan terbesar didunia karena Kerjasama ini menyatukan negara-negara kawasan dengan perekonomian yang besar. Penghasilan secara total dari negara anggota RCEP Menyumbang 30\% PDB dengan spesifikasi $\$ 24,7$ trilliun pada tahun 2019. Sedangkan FDI yang masuk pada negara-negara anggota sebesar $\$ 379$ Miliar. Hal ini tentunya dobrakan baru untuk perekonomian dunia pasca pandemi karena mengintegrasikan perekonomian dunia berskala raksasa. (Gandara, 2020). RCEP ini awalnya di inisiasi pada tahun 2012 pada ASEAN summits ke-21 di Phnom Penh dan berlanjut pada negosiasi serta perundingan pada tahun-tahun selanjutnya. RCEP Pada awal keanggotaan RCEP ini terdiri dari 16 Negara, yaitu 10 Negara anggota ASEAN dan 6 Negara pihak FTA (China, Jepang, Australia, India, Selandia Baru, Korea Selatan. Namun dalam perkembangannya India menarik diri dari keanggotaan RCEP karena beberapa hal. Salah satunya ialah kekhawatiran atas FTA China. India khawatir impor barang dari china akan membanjiri pasar domestiknya daripada ekspor dari india ini sendiri. (Khalil, 2021) Mengingat pasar china kurang kooperatif untuk barang-barang yang berasal dari india. Selain itu jika melihat perkembangan dari pendirian RCEP, China sangat tertarik terhadap RCEP ini. Karena China dan jepang sangat ingin mempercepat pelaksanaan RCEP dan China berusaha memainkan peran aktif dalam RCEP ini, Seperti memimpin perundingan-perundingan dalam pembentukan RCEP. (Arham, 2017). Hal ini menunjukan bergabungnya China dalam RCEP terdapat kepentingan dan Motif yang besar oleh china. Berikut Analisis Kepentingan China dalam percepatan RCEP.

1) Counter Balance Terhadap AS atas TPP (Trans Pacific Partnership)

Tindakan China dalam mengusung percepatan pembentukan RCEP ini sangat sesuai dengan konsep Balance of power. Dalam teori neorealis menjelaskan bahwa dunia internasional ini bersifat anarkis yang mana power adalah inti dari semuanya, walaupun teori ini memandang bahwa negara bukanlah aktor satu-satunya. Asumsi dari teori ini negara akan terus melakukan Survive dalam dunia internasional serta mencoba mengambil keuntungan semaksimal mungkin dan berusaha mendapatkan power. Sedangkan sikap balancing ini terjadi karena melihat negara-negara lain dirasa tidak aman dan membahayakan. Sehingga timbul Balance of Power untuk menguatkan dan berusaha menyeimbangkan power dan Rebalancing of power atau counterbalance untuk merespon balance of power. (MARSA, 2015)

Tindakan Amerika dengan mengeluarkan Pivot to Asia dengan tujuan mendapatkan pengaruh di kawasan Asia Pasifik, hal ini direalisasikan dengan bergabungnya AS dalam Trans Pacific Partnership (TPP) sebagai Regional Trade Agreement. Bergabungnya AS 
dalam TPP membawa pengaruh yang signifikan, seperti AS mulai dapat mendominasi dan berperan aktif dalam TPP. Beberapa perubahan terjadi ketika Hadirnya AS di TPP, yaitu;

a. Dalam Laporan Congressional Research Service pada Mei dan Juli 2013. AS mendorong liberalisasi TPP menjadi lebih Komprehensif dan dan memiliki standar tinggi dengan menyerupai aturan WTO.

b. TPP menambahkan anggota yaitu Jepang, Kanada dan Mexico. Pada saat itu AS mengirim undangan kepada jepang untuk bergabung dalam TPP. Melihat pada saat itu Jepang sedang memiliki konflik wilayah dengan Tiongkok di laut china timur. Hal ini secara tidak langsung menunjukan bahwa AS mencari sekutu dalam memperkuat posisinya. Dalam regionalisasi TPP Melibatkan 11 negara anggota yang bersekutu dengan AS serta beberapa peraturan perdagangan baru yang menguntungkan AS. Sehingga sangat terlihat bahwa AS berusaha Mempengaruhi dan mendominasi Perekonomian Asia Pasifik.

Mengetahui hal tersebut, China berusaha meng-counterbalance atas pengaruh besar AS di asia Pasifik lewat TPP. Bergabungnya China dalam RCEP merupakan tindakan besar untuk memperluas pengaruh China di Asia Pasifik untuk menyaingi pengaruh AS di TPP. Strategi china terlihat melakukan rebalancing dalam RCEP(The Regional Comprehensive Economic Partnership) ialah pada saat perundingan akan pendirian RCEP. China berperan besar sebagai negara kunci diproses negosiasi saat perundingan RCEP. Dalam perundingan China sangat mengupayakan RCEP ini agar cepat dilaksanakan dan mempromosikan dukungan besar atas RCEP. Jika kita menganalisa lebih jauh, tindakan china dalam RCEP ini juga merupakan penyeimbangan pasar asia timur dan memperat ekonomi china dengan negara-negara anggota TPP. Mengingat setengah anggota ASEAN bergabung dalam TPP, Seperti Brunei, Singapura, Vietnam dan Malaysia. Tentunya China akan mengupayakan peranya dalam RCEP karena menurut para analisis dari China menjelaskan bahwa RCEP merupakan strategi yang paling relevan dalam Counterbalance terhadap AS atas TPP, ditambah RCEP terlihat lebih menjanjikan dari pada TPP. Pasalnya Kemitraan RCEP adalah proses integrasi ekonomi yang lebih besar dalam menghilangkan hambatan tarif dan peraturan yang lebih longgar dibanding TPP. Pasalnya Kemitraan RCEP integrasi ekonomi yang lebih besar karena Negara RCEP menyumbang 30\% PDB dunia serta peraturan RCEP yang lebih longgar dibanding TPP sehingga sangat menguntungkan terhadap negara besar dan negara berkembang maupun kecil.

Hal lain yang menguatkan tindakan China dalam melakukan Counter balance terlihat pola dari kebijakan-kebijakan yang china ambil. Pada tahun 2013 China memprakarsai bank pembangunan yaitu Infrastructure and Investment Bank. Terdiri dari 58 negara menjadi bagian dari pendirian AIIB ini. Hal ini menunjukan AIIB sebagai Sarana China dalam menguatkan pengaruhnya nya di kawasan Asia Pasifik, mengingat China negara pemrakarsa dan juga berperan sebagai negara pendonor. Selain itu china juga berusaha mengundang negara-negara sekutu AS untuk menjadi bagian dari AIB seperti Australia dan Korea Selatan sebagai bentuk Counterbalance. 


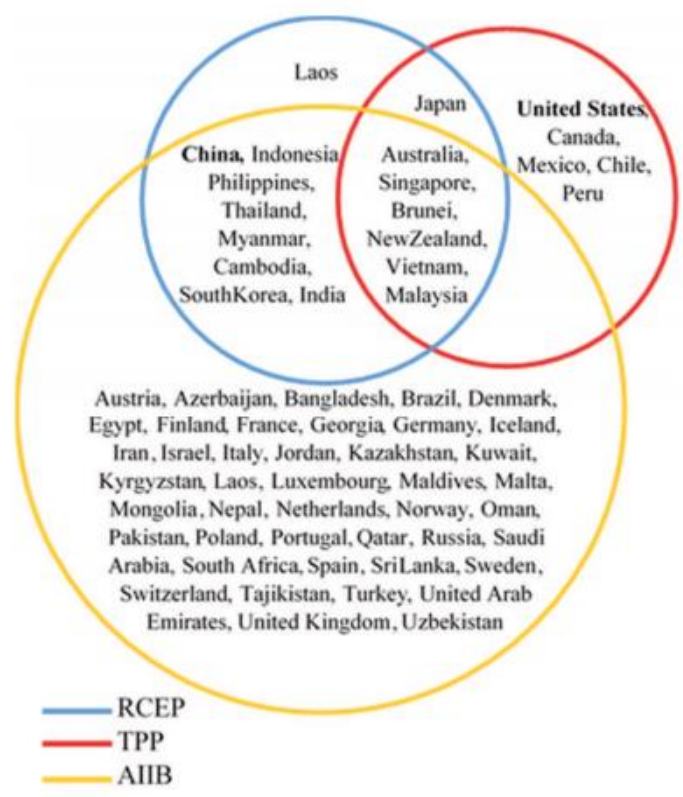

Dalam analisis pola ini menjelaskan bahwa china berhasil dalam menguatkan pengaruh di kawasan Asia Pasifik serta berusaha menyeimbangi kekuasaan AS atas TPP. Serta mengurangi dampak negatif ekonomi yang dilakukan AS dalam TPP dikawasan Asia Pasifik. (Atmadja, 2021)

2) Menciptakan Citra Positif dan Memperbaik dan Memperkuat Hubungan Negara ASEAN

Song Guoyou berpendapat bahwa bukan hanya aspek ekonomi yang dapat mengamankan kawasan asia pasifik. Aspek lain yang tidak kalah penting ialah memperbaiki hubungan dengan negara lain. Bergabungnya China dalam RCEP atau perjanjian internasional adalah langkah awal dalam memperbaiki dan meredakan hubunganya dengan negara lain. Sehingga menjalin hubungan erat antara china dan negaranegara anggota RCEP terkhusus anggota ASEAN adalah tujuan politik china. Mengulas kembali dari pendirian RCEP bahwa China sangat bersemangat akan pembentukanya dan mengusung untuk mempercepat pelaksanaan RCEP. Hal ini dapat dijelaskan bahwa Posisi China di kawasan Asia Tenggara sedang tidak baik-baik saja. Melihat konflik atau laut China selatan yang terjadi puluhan tahun, dikhawatirkan dalam mengganggu China sebagai kekuatan regional terhadap perekonomianya dan tujuan strategis china lainya. Dengan bergabungnya ke RCEP merupakan tindakan mempererat hubungan dengan negara tetangga dan menawarkan ekonomi yang saling menguntungkan. (Atmadja, 2021)

Hal ini dapat diartikan bahwa china berusaha menciptakan Citra Positif di wilayah kawasan Asia Pasifik terkhusus asia tenggara. Teori neorealis menjelaskan bahwa Negara akan melakukan kerjasama atau terjalin dalam perjanjian internasional membawa kepentingan masing-masing. Ekonomi dan citra positif dua hal yang tidak dapat dipisahkan dalam kepentingan china di RCEP. Tindakan China lainya dalam mengupayakan citra Positif di RCEP ialah berusaha mengambil peran aktif dalam negosiator, memimpin perundingan-perundingan dalam RCEP dan mendukung serta mempromosikan RCEP. Kemurahan hati lainya yang dilakukan China terhadap kawasan Asia tenggara ialah pada Kerjasama ASEAN-China(ACFTA) dengan tujuan menampung keinginan ASEAN bekerja sama dengan China. Selain itu RCEP ini juga mempererat hubungan China dan Filipina dan sebuah akselerasi hubungan ekonomi jangka panjang. Bahwa kebijakan serta politik luar negeri dapat berubah-ubah tergantung siapa yang memimpin negara tersebut. Terikatnya China dan Filipina dalam RCEP dapat mempertahankan persahabatan mereka walaupun jika 
Pemimpin negara Filipina Presiden Rodrigo R. Duterte pada tahun 2022. Sehingga Kerjasama bilateral antar negara ini tetap terjalin dan menciptakan kerjasama strategis yang lebih kompershing di abad ke 21 hingga Masa Presiden Duterte berakhir. RCEP menjelaskan bahwa walaupun merupakan kerjasama multilateral tetapi dapat menjadi peluang untuk china mempererat hubungan bilateral. Karena RCEP bukan hanya memperkuat antarinstitusi Filipina-China namun government to government. Sehingga China memiliki peluang dalam RCEP untuk memperbaiki hubunganya dengan negara tetangga serta memperat hubungan dengan negara Tetangga. (PIPVTR, 2020).

3) Pasar Baru China di Asia Pasifik

Keanggotaan RCEP yang terdiri dari 10 Anggota Asean dan 5 Negara FTA(China, Jepang,Australia, Korea Selatan dan Selandia baru) menciptakan 30\% PDB Dunia yaitu $\$ 24,7$ Triliun di tahun 2019. Integrasi Ekonomi ini seperti yang dijelaskan sebelumnya, bahwa partnership terbesar didunia. Namun jika kita melihat kilas lebih jauh, terbentuknya RCEP ini merupakan Pasar baru untuk China. Terkhusus negara-negara anggota FTA (Australia, Jepang dan Selandia baru) dan negara-negara Asean yang memiliki hubungan kurang baik dengan China. Namun dengan partnership RCEP menjadikan pasar baru yang sebelumya china belum mendapatkan akses disana. Contoh yang paling kongkrit antara Kerjasama Free Trade Area antara China dan Jepang. Jepang sebelumnya sudah melakukan free trade dengan ASEAN dalam ASEAN+3 dan jepang juga terikat free trade area dengan negara saingan China yaitu Amerika Serikat. Sehingga dengan adanya RCEP menjadikan pasar baru untuk China dalam mengekspansikan perekonomianya. (Gandara, 2020).

Beberapa hasil kebijakan dari FTA RCEP antara China-Jepang yang melahirkan kebijakan pemotongan tarif dari china menjadi 0 ke $88 \%$ barang dari jepang. Sedangkan jepang akan memangkas tarik menjadi 0 pada $88 \%$ barang-barang dari china. dibawah kebijakan RCEP ini akan menghapus produk impor antar kedua negara secara bertahap selama 20 tahun. Selain itu setelah berlakunya RCEP terdapat beberapa arus ekspor-impor yang terjadi antara China-Jepang. Jepang mengekspor Plastik, Mineral. Tekstil, bahan kimia, logam, dan pakaian. Sedangkan China mengekspor karet, pakaian, tekstil, karet dan bahan Kimia. (Zhang, 2021). Data tersebut menjelaskan bergabungnya China ke RCEP menjadikan pasar baru untuk china seperti dengan jepang yang sebelumnya kurang ter liberalisasi perdagangan. Karena Jepang dan China sebelumnya tidak pernah terika Free Trade Area melainkan hanya mengikuti Prinsip Most Favorite Nation dalam kebijakan Impor-Ekspor yang ditetapkan oleh WTO.

\subsection{Dampak Kerja Sama RCEP bagi China}

Adanya Regional Comprehensive Economic Partnership (RCEP) memudahkan China membuat tatanan Geo-ekonomi baru yang Asia-Sentris, hal ini ditandai dengan penggunaan alat ekonomi dalam mencapai tujuan strategis. Pengaruh dari China di kawasan Asia Pasifik setelah adanya kesepakatan RCEP ini terus meningkat. Dari kesepakatan RCEP ini penerima manfaat terbesar merupakan China, Jepang dan Korea Selatan melalui kerja sama ekonomi baru, selain itu ASEAN sendiri sudah memiliki kerja sama perdagangan dengan ketiga negara tersebut. RCEP sebagian besar dibangun melalui perjanjian secara sepihak dengan mitra dagangnya dengan menciptakan satu blok besar yang meningkatkan interaksi perdagangan. Dengan dibentuknya RCEP merupakan kemenangan China secara tidak langsung dan menjadi negara yang lebih kooperatif dan kolaboratif dibandingkan Amerika Serikat di kawasan Asia Pasifik. Amerika Serikat yang bukan bagian dari RCEP dan keputusan dari Presiden Trump yang menyatakan untuk keluar dari Trans Pacific Partnership (TPP) pada 2017 sehingga merubah peta geopolitik di kawasan Asia secara besar-besaran, dengan fakta tersebut menjadi peluang untuk China dalam penyeimbangan kekuatan di kawasan Asia Timur. (Anand, 2021). Dengan 
besarnya kekuatan China dalam RCEP sehingga memunculkan berbagai dampak terhadap China.

1) RCEP Memiliki Kawasan Besar dan Integrasi yang Baik

Kawasan yang membentuk RCEP merupakan wilayah yang memiliki integrasi yang baik secara ekonomi serta kesepakatan perdagangan dalam kawasan tersebut. China merupakan pasar terbesar bagi seluruh negara kawasan mengingat China merupakan negara dengan populasi terbesar di dunia, selain itu China merupakan pemasok impor utama. Manfaat yang didapatkan dari liberalisasi perdagangan melalui RCEP kemungkinan hanya menyebar secara tidak merata dan yang paling diuntungkan adalah tiga negara terbesar yaitu China, Jepang dan Korea Selatan dibandingkan negara-negara ASEAN. Peraturan yang ada dalam RCEP harus longgar karena tingkat perkembangan dari anggotanya yang luas, sehingga RCEP ini cukup berbeda dibandingkan dengan Comprehensive and Progressive Trans-Pacific Partnership (CPTPP) yang lebih preskriptif. RCEP juga memiliki sedikit peraturan mengenai subsidi industri atau perusahaan milik negara, sehingga mengacu pada keinginan Pemerintah China di Beijing dalam memberi perlindungan terhadap perekonomian domestik di China.

Ketentuan RCEP juga harus longgar mengingat tingkat perkembangan yang luas di antara para anggotanya. Dengan demikian, cukup berbeda dengan Comprehensive and Progressive Trans-Pacific Partnership (CPTPP) yang lebih preskriptif, yang mulai berlaku pada akhir 2018. Berbeda dengan CPTPP, misalnya, ketentuan perdagangan digitalnya tipis. Masalah pertanian dan tenaga kerja juga hampir tidak ditangani. RCEP juga memiliki sedikit substantif untuk dikatakan tentang subsidi industri atau perusahaan milik negara, hampir pasti mengacu pada keinginan Beijing untuk melindungi alat manajemen ekonomi domestiknya sendiri. Berbeda dengan CPTPP, RCEP akan memicu beberapa reformasi struktural yang mendorong pertumbuhan dalam jangka panjang.

2) Peran China Sebagai Pembentuk Peraturan dalam RCEP Meningkat

Pengesahan RCEP memantapkan kemenangan geopolitik China secara signifikan, sehingga kesepakatan ini memperkuat sikap saling ketergantungan ekonomi di kawasan Asia. China dengan kekuatan ekonomi yang besar menjadi pusat dari perekonomian di kawasan RCEP, dengan fakta tersebut pemerintah China akan menggunakan kekuatan ekonominya untuk memberi pengaruh di kawasan dan dapat menetapkan peraturan dalam RCEP, seperti yang terjadi dalam One Belt One Road. Kesepakatan mengenai efisiensi rantai pasokan menimbulkan daya tarik dari kawasan ini oleh para investor asing sehingga memperkuat ketahanan China dalam menghadapi ketegangan perang dagang. (Ward, 2020).

3) Meningkatkan Bisnis China

Bisnis di China mendapatkan manfaat ekonomi yang signifikan dengan adanya RCEP. China sebagai kekuatan ekonomi terbesar dalam kawasan ini kemungkinan menjadi satu-satunya yang menerima manfaat ekonomi dengan adanya perjanjian ini, terutama dengan keluarnya India dari RCEP memperbesar peluang China dalam menguasai perekonomian di kawasan RCEP. Dalam RCEP tidak ada batasan yang menjadi penghalang bagi China. Pasar yang tercipta dari RCEP merupakan pasar yang terus berkmbang dan dinamis di seluruh kawasan Asia Tenggara, hal ini memberi keuntungan untuk industri ekspor China ke kawasan Asia Tenggara. Hasil dari RCEP ini dalam ekspor China mengalami peningkatan sebesar US\$248 miliar, selain itu perjanjian ini mendukung strategi "dual circulation" dan Five Years Plan (FYP) ke-14 China yang tujuannya untuk mengarahkan permintaan dalam negeri China dan mendukung interaksi internasional dengan investor asing. (Yee, 2021). 
Salah satu industri di China yang mengalami peningkatan setelah pelaksanaan RCEP adalah industri pertambangan. Dalam RCEP mencakup total 2,3 miliar orang, total PDB lebih dari US\$25 triliun yang menyumbang 25\% dari jumlah perdagangan global, sehingga RCEP ini akan menjadi perjanjian perdagangan bebas yang terbesar dan memiliki pengaruh yang sangat besar di dunia. Melalui perspektif pertambangan walaupun RCEP tidak terlalu berpengaruh dalam pertambangan Minyak Bumi dan Gas Alam yang masih cukup besar, dalam perkembangannya di masa depan akan terus dikembangkan secara bertahap dan diselesaikan satu demi satu. Pasar pertambangan China bisa dikatakan mempunyai peluang yang lebih besar dibandingkan hambatannya. Walaupun begitu China tetap bersiap untuk menghadapi perubahan di masa depan yang mungkin terjadi dalam ekspor dan impor tambang. Akses pasar yang telah diamankan dan terverifikasi oleh RCEP akan membantu pertumbuhan lapangan kerja dan permintaan dalam negeri China, pemerintah China menawarkan kepada perusahaan dalam negeri yang mengalami kesulitan ekonomi dikarenakan perang dagang dengan Amerika Serikat dan pandemi Covid-19. PDB China pada 2019 tumbuh sebesar 6,1\% yang merupakan pertumbuhan paling lambat selama tiga dekade terakhir, hal ini disebabkan sulitnya China menembus pasar Amerika Serikat akibat dari perang dagang, yang mana merupakan mitra dagang terbesar bagi China. Walaupun RCEP bukanlah suatu solusi yang komprehensif, tetapi diperkirakan akan mengurangi kerugian China sebesar US\$304 miliar dari perang dagang.

Dengan adanya RCEP melalui faktor-faktor seperti liberalisasi perdagangan regional yang cukup menguntungkan dan meningkatnya perkiraan inflasi global, industri pertambangan China terutama industri logam diharapkan akan membawa peningkatan perekonomian dan pembangunan China. Peluang jangka pendek, dengan persediaan logam dasar yang relatif sedikit, ketatnya keseimbangan antara pasokan dan permintaan karena rendahnya belanja modal diperkirakan akan menciptakan kesenjangan pasokan dalam proses peningkatan pembangunan infrastruktur pasca pandemic dan harga yang naik akan memberi keuntungan yang lebih besar. Peluang jangka panjang, setelah ditandatanganinya RCEP membuat kondisi perdagangan berangsur membaik. Setelah aksesi China ke WTO, efek stimulus yang timbul karena perdagangan dan ekonomi global diharapkan secara bertahap akan masuk ke Asia Tenggara dan negaranegara lain melalui RCEP untuk lebih mendorong alokasi optimal kapasitas produksi industri primer global, yang kondusif bagi pendalaman pembangunan infrastruktur secara berkelanjutan di negara-negara terkait. Selain itu, perlu untuk mempromosikan titik pertumbuhan permintaan logam non-ferrous untuk secara bertahap beralih ke negaranegara Asia Tenggara. Selain itu, ini akan membawa titik pertumbuhan konsumsi baru dan kekuatan pendorong berkelanjutan untuk logam industri untuk lebih meningkatkan tingkat penilaian perusahaan pertambangan terkait. Dan perlu untuk mempromosikan titik pertumbuhan permintaan logam non-ferrous untuk secara bertahap beralih ke negaranegara Asia Tenggara. Selain itu, ini akan membawa titik pertumbuhan konsumsi baru dan kekuatan pendorong berkelanjutan untuk logam industri untuk lebih meningkatkan tingkat penilaian perusahaan pertambangan terkait. Dan perlu untuk mempromosikan titik pertumbuhan permintaan logam non-ferrous untuk secara bertahap beralih ke negaranegara Asia Tenggara. Selain itu, ini akan membawa titik pertumbuhan konsumsi baru dan kekuatan pendorong berkelanjutan untuk logam industri untuk lebih meningkatkan tingkat penilaian perusahaan pertambangan terkait. ( $\mathrm{Lu}, 2021)$.

4) Dominasi Teknologi Tinggi China

RCEP akan memudahkan pertukaran peralatan yang berteknologi tinggi antara China, Korea Selatan, dan Jepang sehingga dapat membantu China mengejar MIC2025, inisiatif kebijakan yang dipimpin negara dengan tujuan "mengubah China menjadi 
pemimpin kekuatan manufaktur pada tahun 2049." Tujuan ini sejalan dengan pengembangan teknologi strategis seperti semikonduktor dan infrastruktur digital lainnya yang telah dipersiapkan dalam FYP ke-14 untuk 2021-2025.

RCEP sendiri kurang komprehensif dibandingkan dengan CPTPP. RCEP hanya menawarkan ketentuan yang relatif lunak tentang pengurangan tarif yang memungkinkan negara-negara anggota untuk mempertahankan tarif pada industri yang dianggap sangat penting atau sensitif. Tingkat fleksibilitas RCEP ini mencerminkan keanggotaannya yang beragam, yang mencakup ekonomi yang kuat seperti China dan yang kurang berkembang seperti Kamboja dan Laos. Walaupun begitu, ketentuan luas seperti itu memungkinkan China untuk mempertahankan keunggulan rantai pasokannya yang masih ada dan secara strategis mempromosikan industri domestik yang baru lahir seperti teknologi kendaraan listrik. Sementara China segera menghapus petak tarif yang luas di industri di mana ia telah mempunyai keunggulan kompetitif, tarifnya di sekitar kendaraan listrik yang ditetapkan sebagai "industri baru yang strategis" oleh pemerintah pusat dan prioritas utama MIC2025 dan FYP ke-14 memberitahukan hal berbeda. Melalui RCEP, China tidak harus untuk menghapus tarif pada elektroda dan bahan tertentu untuk baterai mobil listrik hingga tahun 2036. Hal ini memungkinkan China untuk secara taktis melindungi sektor teknologi tinggi tertentu dari persaingan asing.

5) China Menguasai Multilateralisme dan Pasar Bebas

Saat RCEP akan memperluas manfaat perdagangan dan ekonomi yang signifikan bagi China, pengaruh terbesarnya yaitu memperkuat reputasi China sebagai negara yang menguasai internasionalisme sehingga memperkuat pengaruh geopolitiknya. Perdana Menteri China Li Keqiang menggambarkan RCEP sebagai "Kemenangan atas multilateralisme dan pasar bebas." Gambaran ini berbanding terbalik dengan Amerika Serikat ketika era Trump yang secara sepihak meninggalkan TPP. Selain itu, permasalahan tidak adanya kepemimpinan Amerika Serikat di kawasan Asia-Pasifik akan sulit untuk segera diatasi oleh pemerintahan baru, sentiment proteksionis masih tinggi di Amerika Serikat, dan Presiden terpilih Binden masih belum memiliki rencana untuk bergabung dengan RCEP atau CPTPP. Saat pemerintahan Amerika Serikat yang terbaru mencoba untuk

Selain itu, masalah tidak adanya kepemimpinan perdagangan Amerika Serikat di Asia-Pasifik tidak mungkin segera diatasi oleh pemerintahan baru, sentimen proteksionis tetap tinggi di Amerika Serikat, dan Presiden terpilih Biden pada dasarnya tetap diam tentang rencana untuk bergabung dengan RCEP atau CPTPP. Ketika pemerintahan terbaru Biden mencoba untuk meyakinkan pemilih kerah biru dan progresif tentang manfaat perdagangan internasional secara bersamaan terperosok dalam memerangi krisis kesehatan masyarakat terburuk dalam lebih dari satu abad tetapi China terus mengejar perjanjian multilateral. Lima hari setelah penandatanganan RCEP, Xi Jinping mengatakan bahwa China akan "mempertimbangkan dengan baik" untuk bergabung dengan CPTPP. Beijing juga baru-baru ini menyelesaikan perjanjian investasi besar China-Uni Eropa dan berjanji untuk "mempercepat negosiasi" pada perjanjian perdagangan bebas China-Jepang-Korea. (Yee, 2021).

\section{KESIMPULAN}

Awal mula terbentuknya Regional Comprehensive Economic Partnership (RCEP) dikarenakan konflik yang terjadi antara China dan Jepang. Cina dan Jepang memiliki pandangan yang berbeda tentang struktur ekonomi regional yang paling tepat dalam hal keanggotaan dan agenda. Perjuangan antara keduanya untuk dominasi regional dapat ditelusuri kembali tidak lama setelah krisis keuangan Asia yaitu pada tahun 1997/1998. China dan Jepang membuat proposal bersama tentang 
kerjasama ekonomi Asia Timur pada Agustus 2011. Mereka menyarankan pembentukan Kelompok Kerja, di mana EAFTA dan CEPEA dapat dibahas, sebelum akhir 2011 untuk mencakup topiktopik berikut: (i) perdagangan barang, (ii) perdagangan jasa, dan (iii) investasi. Sebagai buku aturan tunggal, RCEP memiliki nilai tambah dan dapat mendorong pengembangan dan perluasan rantai pasokan antar anggota. Perjanjian tersebut mencakup kerjasama teknis dan pengembangan kapasitas untuk mendukung tindakan mereka berdasarkan perjanjian. Adapun manfaat yang didapat jika bergabung seperti yang paling utama adalah tentang perdagangan barang. Kontribusi utama RCEP dalam perdagangan barang adalah menggabungkan kesepakatan yang ada, yang membawa Asia selangkah lebih dekat ke blok perdagangan regional. Pada tahun 2018, RCEP belum menyelesaikan negosiasi antara 16 negara. Hingga tahun 2019, ke-16 negara tersebut masih belum menyelesaikan negosiasi RCEP karena ditentang oleh India, seorang pejabat India mengatakan bahwa India tidak dapat bergabung dengan RCEP berdasarkan ketentuannya saat ini, dan India tidak berpartisipasi dalam pertemuan negosiasi berikutnya.

Berdirinya RCEP ialah menciptakan kesepakatan perdagangan terbesar didunia karena Kerjasama ini menyatukan negara-negara kawasan dengan perekonomian yang besar. Penghasilan secara total dari negara anggota RCEP Menyumbang 30\% PDB dengan spesifikasi \$24,7 triliun pada tahun 2019. Sedangkan FDI yang masuk pada negara-negara anggota sebesar \$379 Miliar. Hal ini tentunya dobrakan baru untuk perekonomian dunia pasca pandemi karena mengintegrasikan perekonomian dunia berskala raksasa. Kepentingan China dalam RCEP, yaitu Counter Balance Terhadap AS atas TPP (Trans Pacific Partnership). Tindakan China dalam mengusung percepatan pembentukan RCEP ini sangat sesuai dengan konsep Balance of power. Dalam teori neorealis menjelaskan bahwa dunia internasional ini bersifat anarkis yang mana power adalah inti dari semuanya, walaupun teori ini memandang bahwa negara bukanlah aktor satu-satunya. Tindakan Amerika dengan mengeluarkan Pivot to Asia dengan tujuan mendapatkan pengaruh di kawasan Asia Pasifik, hal ini direalisasikan dengan bergabungnya AS dalam Trans Pacific Partnership (TPP) sebagai Regional Trade Agreement. Mengetahui hal tersebut, China berusaha mengcounterbalance atas pengaruh besar AS di asia Pasifik lewat TPP. Bergabungnya China dalam RCEP merupakan tindakan besar untuk memperluas pengaruh China di Asia Pasifik untuk menyaingi pengaruh AS di TPP. Selain itu China berusaha untuk Menciptakan Citra Positif dan Memperbaiki dan Memperkuat Hubungan Negara ASEAN. Song Guoyou berpendapat bahwa bukan hanya aspek ekonomi yang dapat mengamankan kawasan asia pasifik. Aspek lain yang tidak kalah penting ialah memperbaiki hubungan dengan negara lain. Hal ini dapat diartikan bahwa china berusaha menciptakan Citra Positif di wilayah kawasan Asia Pasifik terkhusus asia tenggara. Teori neorealis menjelaskan bahwa Negara akan melakukan kerjasama atau terjalin dalam perjanjian internasional membawa kepentingannya masing-masing. Ekonomi dan citra positif dua hal yang tidak dapat dipisahkan dalam kepentingan china di RCEP. Keanggotaan RCEP yang terdiri dari 10 Anggota Asean dan 5 Negara FTA(China, Jepang, Australia, Korea Selatan dan Selandia baru) menciptakan 30\% PDB Dunia yaitu \$24,7 Triliun di tahun 2019. Integrasi Ekonomi ini seperti yang dijelaskan sebelumnya, bahwa partnership terbesar didunia. Namun jika kita melihat kilas lebih jauh, terbentuknya RCEP ini merupakan Pasar baru untuk China. Adanya Regional Comprehensive Economic Partnership (RCEP) memudahkan China membuat tatanan Geo-ekonomi baru yang Asia-Sentris, hal ini ditandai dengan penggunaan alat ekonomi dalam mencapai tujuan strategis. Pengaruh dari China di kawasan Asia Pasifik setelah adanya kesepakatan RCEP ini terus meningkat. Dampak RCEP bagi China cukup menguntungkan China diantaranya adalah RCEP memiliki kawasan besar dan integrasi yang baik, peran China sebagai pembentuk peraturan dalam RCEP meningkat, meningkatkan bisnis china, dominasi teknologi tinggi China dan kemenangan China dalam multilateralisme dan pasar bebas. 


\section{DAFTAR PUSTAKA}

Anand, K. (2021, April 27). China-led RCEP to change global order? Retrieved Oktober 23, 2021, from Observer Reseaech Foundation: https://www.orfonline.org/expert-speak/china-ledrcep-to-change-global-order/

Arham, A. A. (2017, Agustus 21). Keikutsertaan China Dalam Regional Comprehensive Economic Partnership Sebagai. Retrieved Oktober 22, 2021, from Repositoryumy: http://repository.umy.ac.id/bitstream/handle/123456789/13870/JURNAL.pdf?sequence=11 \&isAllowed $=\mathrm{y}$

Atmadja, S. (2021). STRATEGI CHINA Amerika Serikat dilihat sebagai pihak yang berkeinginan untuk mendominasi kawasan Asia Pasifik. Retrieved Oktober 22, 2021, from Anzdoc: https://adoc.pub/bab-iii-strategi-china.html

BRIEFS, A. (2020). Regional Comprehensive Economic Partnership: Overview and Economic Impact. ADB BRIEFS NO.164, 2-5.

Dugis, V. (2016). Teori Hubungan Internasional Perspektif-Perspektif Klasik. Surabaya: Cakra Studi Global Strategis.

Gandara, S. C. (2020, December). Kerja Sama Regional Comprehensive Economic Partnership. Perkembangan Ekonomi Keuangan dan Kerjasama International Edisi IV 2O20, p. 49.

Hamanaka, S. (2014). TPP versus RCEP: Control of Membership and Agenda Setting. Journal of East Asian Economic Integration Vol. 18, No. 2, 163-186.

Khalil, A. (2021, Januari 5). Mengapa India menarik diri dari RCEP? Inilah alasan sebenarnya ...! | Alasan mengapa India keluar dari kesepakatan perdagangan RCEP. Retrieved Oktober 23, 2021, from Poupnews: https://www.poupnews.com/mengapa-india-menarik-diri-darircep-inilah-alasan-sebenarnya-alasan-mengapa-india-keluar-dari-kesepakatan-perdaganganrcep/

Lu, Z. (2021). Analysis of the Impact of RCEP on China's Mining Market. Probe - Environmental Science and Technology, 1-5.

MARSA, M. (2015, September 26). STRATEGI CHINA DALAM MERESPON DOMINASI AS TERHADAP TRANS-PACIFIC PARTNERSHIP (TPP). Retrieved Oktober 23, 2021, from Marsyablog: https://marsyaholmes.blogspot.com/2015/09/strategi-china-dalam-merespondominasi.html

Narine, S. (2003). THE IDEA OF AN "ASIAN MONETARY FUND": THE PROBLEMS OF FINANCIAL INSTITUTIONALISM IN THE ASIA-PACIFIC. Asian Perspective Vol. 27, No. 2, pp. 65-103.

PIPVTR. (2020, November 27). RCEP And Promotion Of Practical Cooperation Between China And Philippines - OpEd. Retrieved Oktober 23, 2021, from EurasiaRiview: https://www.eurasiareview.com/27112020-rcep-and-promotion-of-practical-cooperationbetween-china-and-philippines-oped/

Secretariat, A. (2020, November 15). ASEAN Hits Historic Milestone with Signing of RCEP. Retrieved from ASEAN Secretariat: https://asean.org/asean-hitshistoric-milestone-signingrcep/

Secretariat, A. (2020, November). Summary of the Regional Comprehensive Economic. Retrieved from ASEAN Secretariat: https://asean.org/storage/2020/11/Summary-of-the-RCEPAgreement.pdf

Shimizu, K. (2021). The ASEAN Economic Community and the RCEP in the world economy. Journal of Contemporary East Asia Studies, 14-18.

Syahdani, M. (n.d.). REGIONALISME DALAM REGIONAL COMPREHENSIVE ECONOMIC PARTNERSHIP (RCEP): SEBUAH PERSPEKTIF. 
Trade, A. G. (2020, November 5). RCEP Outcomes: Goods. Retrieved from Australian Government Department of Foreign Affairs and Trade (DFAT): https://www.dfat.gov.au/sites/default/files/rcepoutcomes-goods.pdf.

Ward, R. (2020, November 23). RCEP trade deal: a geopolitical win for China. Retrieved Oktober 23, 2021, from IISS: https://www.iiss.org/blogs/analysis/2020/11/rcep-trade-deal

Yee, W. Y. (2021, Januari 14). The RCEP is a Win for China. Retrieved Oktober 23, 2021, from The China Story: https://www.thechinastory.org/the-rcep-is-a-win-for-china/

Zhang, Z. (2021, Juni 28). Developing Your China Trade with Japan and South Korea Under RCEP. Retrieved Oktober 23, 2021, from China Briefing: https://www.chinabriefing.com/news/developing-your-china-trade-with-japan-and-south-korea-under-rcep/ 